\title{
Electrochemical DNA-sensor for evaluation of total antioxidant capacity of flavours and flavoured waters using superoxide radical damage
}

\author{
M.F. Barroso, C. Delerue-Matos, M.B.P.P. Oliveira
}

\begin{abstract}
A BSTRACT

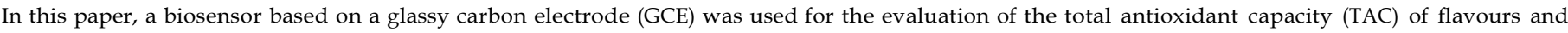

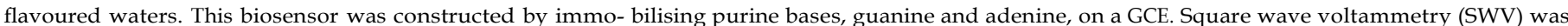

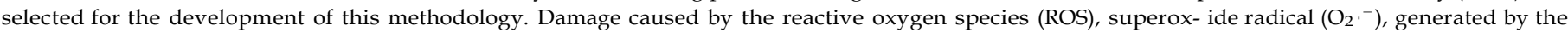

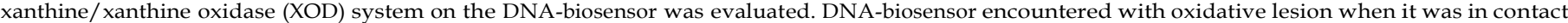

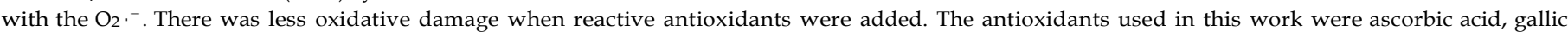

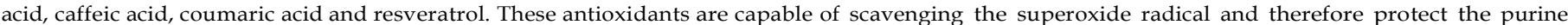
bases immobilized on the GCE surface. The results demonstrated that the DNA-based biosensor is suitable for the rapid assess of TAC in beverages.
\end{abstract}

\section{Keywords:}

DNA biosensor, Total antioxidant capacity (TAC), Ascorbic acid, Phenolic acid, Reactive oxygen species (ROS), Superoxide radical ( $\mathrm{O}_{2} \cdot^{-}$)

\section{Introduction}

Recently, bottled flavoured waters are becoming popular, and the consumption of flavoured waters is globally increasing including Portugal. In the first half of 2010, 6.08 million L of this kind of water were consumed by the Portuguese population (ANIRSF, 2010). Flavoured waters produced from mineral and spring waters consist of the addition of flavours, juices and sugar or sweeteners that provide water with a particular taste and aroma appreciated by consumers. Considering that flavours/aromas are fruit extracts, and fruits are good sources of exogenous antioxidants, it is expected that the use of this fruit extracts in beverages can introduce antioxidants to the water (Barroso et al., 2009, 2011). Antioxidant defence mechanisms include the use of enzymes, vitamins, phenolic compounds, minerals or proteins. Consequently, increasing intake of dietary antioxidants may help maintain an adequate antioxidant status and, therefore, sustain normal physiological functions of a living system. Antioxidants are very important in the mammalian body because they have the ability to combat and reduce oxidative damage caused by reactive oxygen species (ROS) (Halliwell et al., 1992). ROS are continuously produced in all living beings as a result of normal cellular metabolism (Benherlal and Arumughan, 2008).
The superoxide anion radical $\left(\mathrm{O}_{2}{ }^{-}\right)$is the most abundant radical in biological systems resulting from the univalent reduction of oxygen (Ge and Lisdat, 2002). This radical species is enzymatically produced by xanthine oxidase (XOD). XOD is a metalloenzyme that catalyses the oxidation of hypoxanthine and xanthine to form $\mathrm{O}_{2}{ }^{-}$ that is generated during the respiratory burst of phagocytic cells such as neutrophils (Gobi and Mizutani, 2000; Laranjinha, 2009).

Several analytical methods have been proposed for the quantification of the total antioxidant capacity (TAC) in biological and food samples. These methodologies are based on UV-vis spectrometry, chemiluminescence, fluorimetry, electrochemistry and chromatography techniques (Sanchez-Moreno, 2002).

Recently, several electrochemical methods based on enzymatic biosensors have been developed for the determination of superoxide radical and TAC. These biosensors are based on the immobilization of Cytochrome $c$ (this enzyme acts as an oxidant of superoxide radical) or on the immobilization of the enzyme superoxide dismutase (SOD; this enzyme has a protective scavenging function against the superoxide radical), on the electrode surface (gold, platinum, glass, carbon paste or screen printed electrode (SPE), SPE-Au) (Ge and Lisdat, 2002; Emregül, 2005). In this type of protein immobilised biosensor, an electrochemical signal was found to be proportional to the superoxide concentration generated in aqueous solution by the xanthine and xanthine oxidase (Eq. (1)).

xanthine $+\mathrm{H}_{2} \mathrm{O}+\mathrm{O}_{2}-\rightarrow$ uric acid $+2 \mathrm{H}^{+}+\mathrm{O}_{2} \cdot-$ 
For the immobilization of enzymes on an electrode surface, some strategies have been demonstrated. The immobilization of the enzyme can be carried out via short-chain thiol modified gold electrodes, long-chain thiol (mercaptoundecanoic acid), mixed-thiol, long-chain mixed thiol (mercaptoundecanoic acid/mercaptoundecanol) and hemin modified electrode (McNeil et al., 1995; Gobi and Mizutani, 2000; Ignatov et al., 2002). However, the performance of many of these types of devices is interfered by hydrogen peroxide, uric acid and some communication interference between the protein and the electrode (Chen et al., 2000; Beissenhirtz et al., 2004; Endo et al., 2002; Campanella et al., 2004; Emregül, 2005). The protective effect of antioxidants at a cellular level could only be achieved by monitoring the DNA integrity (Barroso et al., 2011). For this purpose, electrochemical DNA-based biosensors have been developed in order to assess the TAC of foodstuff (Mello et al., 2006; Barroso et al., 2011). In many studies (Fojta et al., 2000; Mello et al., 2006), the oxidative damage of double stranded DNA or of the nucleobases (guanine or adenine) by the hydroxyl radical was evaluated. The oxidative damage produces a significant decrease in the current intensity on the strand scission of DNA or on the decreasing oxidation current after damage of the nucleobases (Liu et al., 2005, 2006; Mello et al., 2006; Qian et al., 2010). In this work, a DNA-sensor was used in order to evaluate TAC in bottled flavoured waters. This DNA-biosensor consisted of electrochemically deposited purine base (adenine or guanine) on a glassy carbon electrode (GCE). All DNA bases (purine and pyrimidine) can be used for the electrochemistry study. However, purine bases (adenine and guanine) are more sensitive for detection and present lower potential peaks than the pyrimidine bases $(+1.3 \mathrm{~V}$ for thymine and $+1.5 \mathrm{~V}$ for cytosine). Considering that purine bases have peaks more well-defined and larger than those of the pyrimidines (Brett and Matysik, 1997), the purine bases were used in this study. In experiments evaluating the oxidative damage of the purine bases, the biosensor was firstly immersed in an aqueous superoxide radical solution that was generated in the enzymatic reaction between XOD and xanthine (Eq. (1)). Then, the decrease of the oxidation current of guanine and adenine recorded in square wave voltammetry (SWV) was used to relate the extent of oxidative damage. The influence/protection of five antioxidants, such as, ascorbic acid, gallic acid, caffeic acid, reverastrol and p-coumaric acid was studied.

\section{Materials and methods}

\subsection{Chemicals}

Guanine, adenine, xanthine oxidase (XOD, X1875) xanthine, gallic acid, resveratrol were purchased from Sigma. Caffeic acid was from Fluka, 1(+) ascorbic acid and reveratrol was acquired from Riedeil-de-Haën. Other chemicals were Merck pro-analysis grade and were used as received. Guanine stock solution $\left(1 \mathrm{~g} \mathrm{~L}^{-1}\right)$ was prepared by dissolving an amount of this solid in $0.1 \mathrm{~mol} \mathrm{~L}^{-1}$ of $\mathrm{NaOH}$ and diluting in $\mathrm{pH} 7.4$ phosphate buffered saline (PBS). Stock solution of $1 \mathrm{~g} \mathrm{~L}^{-1}$ of adenine was prepared in PBS $\mathrm{pH} 7.4$ and stored at $+4{ }^{\circ} \mathrm{C}$. For all voltammetric measurements, $\mathrm{pH} 4.8$ PBS was used as the supporting electrolyte. Superoxide radical was generated by adding XOD (0.0015 $\left.\mathrm{U} \mathrm{mL}^{-1}\right)$ to oxygen-satured PBS ( $\left.\mathrm{pH} 7.4\right)$ containing xanthine $\left(10 \mu \mathrm{mol} \mathrm{L}^{-1}\right)$. All solutions were prepared with water purified with a Direct-Q (Millipore) system.

\subsection{Instrumentation}

SWV was performed with an Autolab PSTAT 10 potentiostat controlled by GPES software (EcoChemie, The Netherlands). A conventional three electrode cell was used, which includes a GCE $\left(0.07 \mathrm{~cm}^{2}\right)$ as working electrode, a glassy carbon counter electrode and a $\mathrm{Ag}|\mathrm{AgCl}| \mathrm{KCl}_{\text {sat }}$ reference electrode to which all potentials were referred. The GCE was mechanically polished using a polishing kit (Metrohm 6.2802.010) first with )'- $\mathrm{Al}_{2} \mathrm{O}_{3}(0.015 \mu \mathrm{m})$ until a shining surface was obtained and then rinsed with water. After this step the GCE was treated by applying a fixed potential of $+1.7 \mathrm{~V}$ for $30 \mathrm{~s}$ in PBS $\mathrm{pH}$ 4.8. This initial conditioning step improves the resolution of the analytical signal because the application of high potentials in acidic medium increases the hydrophilic properties of the electrode surface through the introduction of oxygenated functionalities (Rice et al., 1983; Mello et al., 2006).

\subsection{Assay procedure}

Unless otherwise mentioned, all experiments consisted of three steps: (i) Guanine or adenine electro-immobilization on the GCE, (ii) damage of purine bases by the immersion of DNA-GCE in the XOD/xanthine solution, and study of the effect of the presence of antioxidants in the system, and (iii) detection and measurement of the peak current of adenine or guanine in a PBS at $\mathrm{pH}$ 7.4.

Purine bases (adenine or guanine) immobilization was performed by the application of an adsorptive accumulation step. For that, the activated GCE was immersed in PBS pH 4.8 containing $10 \mathrm{mg} \mathrm{L}^{-1}$ of adenine or $3 \mathrm{mgL}^{-1}$ of guanine and a potential of $+0.4 \mathrm{~V}$ was applied for $180 \mathrm{~s}$. The electrode was next rinsed with water. A reported procedure (Marrazza et al., 1999; Chiti et al., 2001; Mello et al., 2006) for cleaning and immobilization step was adopted in this work. DNA damage was carried out by immersing the biosensor in a freshly prepared XOD/xanthine mixture in the absence or in the presence of antioxidant in PBS $\mathrm{pH} 7.4$ for a fixed period of reaction time. Next, the biosensor was immersed in pH 4.8 PBS. SWV was then conducted between $+0.2 \mathrm{~V}$ and $+1.4 \mathrm{~V}$ and the oxidation peak current of guanine and adenine obtained was used as a detection signal. For the electrochemical studies it was considered that the maximum signal current obtained were for the purine base electrochemical signal without damage neither antioxidant effect.

\subsection{Samples}

Thirty-nine water samples corresponding to 10 different brands were purchased in several supermarkets in the North of Portugal and stored in the dark at $+4{ }^{\circ} \mathrm{C}$. Each brand (still or sparkling, mineral or spring water) had different flavours and aromas. The natural water of each brand was also used as control. Sonication was used to eliminate gas from the sparkling water samples. The labels on the water bottles indicate the nutrient information, namely the presence of fruit juice, vitamins, sweeteners and preservatives (Barroso et al., 2009).

Six liquid flavours used in the formulation of some water brands, provided by a producer, were also analysed. The flavours used corresponded to different fruit aromas, including lime, tangerine, strawberry, lemon, apple and gooseberry. These flavours had no description about their chemical or aroma composition, but were known to be present in the flavoured waters used in this study.

\subsection{TAC measurement on beverages}

The purine-based biosensor was applied to the determination of TAC on flavour and flavoured waters. For the measurement of TAC in beverages, $100 \mu \mathrm{L}$ of the flavoured water or $5 \mu \mathrm{L}$ of flavour were diluted in PBS to a final volume of $500 \mu \mathrm{L}$. Then, the DNA-GCE was immersed in the solution and a freshly prepared superoxide radical was added. After $120 \mathrm{~s}$, the biosensor was rinsed and immersed in PBS buffer beforeSWV of guanine and adenine was carried out. 

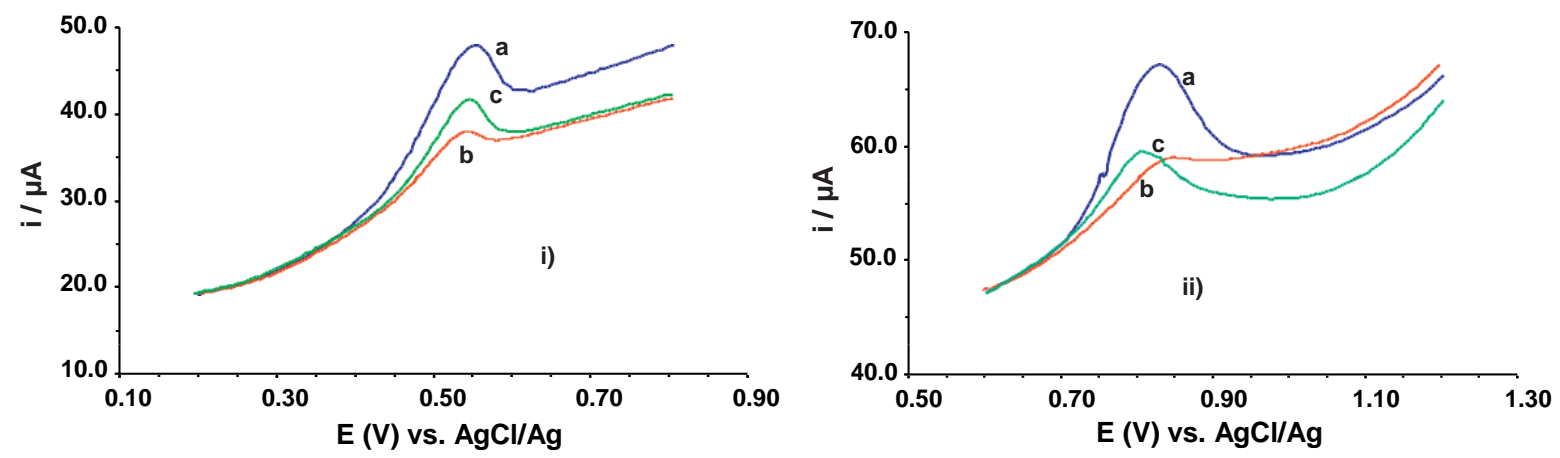

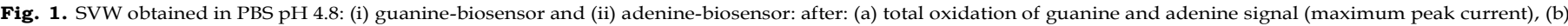
immersion of the biosensor in a superoxide radical solution and (c) immersion in superoxide radical solution with ascorbic acid.

\section{Results and discussion}

The ease of oxidation of purine bases in DNA depends, predominantly, on the secondary structure of the polynucleoside. Owing to the flexibility and better accessibility, nucleobases in a ssDNA are readily oxidised than in a dsDNA, leading to a higher oxidation current at an electrode surface (de-los-Santos-Álvarez et al., 2002). SWV was used to observe the electrochemical response of the oxidation of guanine and adenine immobilised on a GCE. Fig. 1 (curve a in (i) and (ii)) shows the anodic peak of guanine and adenine bases. The less positive peak potential $(+0.55 \mathrm{~V})$ corresponds to the oxidation of guanine, while the peak at more positive potential $(+0.82 \mathrm{~V})$ corresponds to the electrooxidation of adenine. This results are in agreement with $+0.55 \mathrm{~V}$ for guanine and $+0.82 \mathrm{~V}$ for adenine reported in the literature (Brett et al., 1994; Brett and Matysik, 1997), which focussed on the dependence of the oxidation peak of purine bases on $\mathrm{pH}$, buffer and ionic strength. Damage of DNA is the major endogenous type of pathogenesis that induces a variety of diseases including cancer. ROS induced oxidative lesion in the DNA will cause modifications at the DNA. Superoxide radical generated in situ by XOD can mediate the direct strand scission of DNA and this can be attributed to hydrogen atom abstraction of C5, of the deoxyribose (Burrows and Muller, 1998). In order to verify if $\mathrm{O}_{2}{ }^{-}$radicals generated by xanthine/XOD reaction are able to damage purine base immobilized on the GCE, the DNA-GCE was placed in a freshly prepared solution of xanthine/XOD in PBS pH 7.4 for $5 \mathrm{~min}$. Next, the biosensor was rinsed with water and SWV at this biosensor was repeated. A $61.4 \%$ and a $64.5 \%$ decrease in the anodic peak current $\left(i_{\mathrm{p}}\right)$ of guanine and adenine, respectively was observed after the biosensor was immersed on the superoxide radical solution (curve b in Fig. 1i and ii). This decrease in the peak current was used to infer damage of the DNA bases after being oxidised by the $\mathrm{O}_{2}{ }^{-}$radicals. Accord-

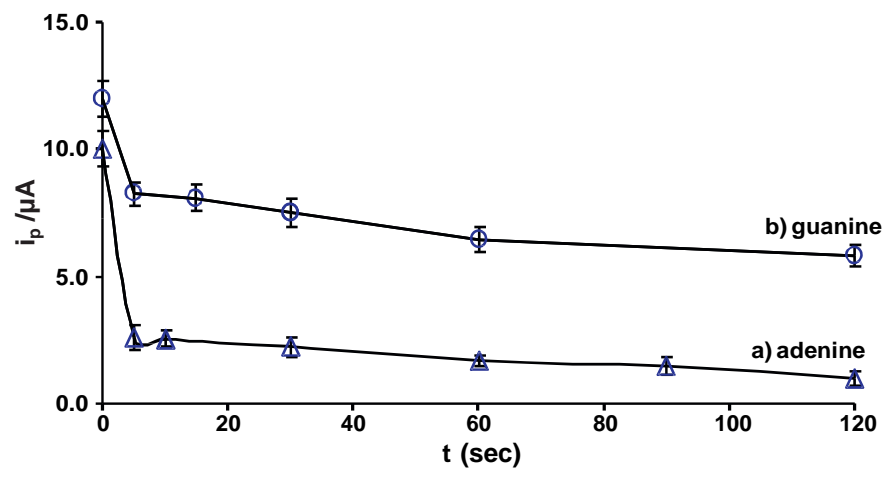

Fig. 2. Influence on the peak current on the biosensor with the incubation time (a) $10 \mathrm{mg} \mathrm{L}^{-1}$ adenine base, (b) $3 \mathrm{mg} \mathrm{L}^{-1}$ guanine base. ing to the literature (de-los-Santos-Álvarez et al., 2007; Freidman and Heller, 2004), guanine base is the most easily oxidized of the nucleic acid base, yielding 8-oxoguanine (8-oxoG) and the tautomer 8-hydroxyguanine. However, a common diiminestructure was produced when guanine and adenine were electrochemically oxidised at neutral or alkaline solution. As shown by curve $\mathrm{c}$ in Fig. $1 \mathrm{i}$ and ii, when an antioxidant, in this case ascorbic acid, was added to the superoxide radical solution a $43.86 \%$ and a $50.11 \%$ increase of $i_{\mathrm{p}}$ of guanine and adenine, respectively, compared to curve b of Fig. $1 i$ and ii. Indeed, this is indicative that the DNA was protected by the antioxidant presents in the solution. Antioxidants are well-known to exhibit a protective effect with a scavenging effect of ROS preventing DNA damage. Consequently, the number of lesions diminishes, yielding a larger number of adenine and guanine for electrochemical oxidation (Barroso et al., 2011). Indeed, ascorbic acid is considered a good scavenger of free radicals produced during the metabolic pathways of detoxification. Ignatov et al. (2002) reported the development of a methodology for the electrochemical detection of antioxidants based on a superoxide radical measurement with a cytochrome $c$ modified electrode. In this study the authors have used several antioxidants such as ascorbic acid (standard antioxidant) and sub-groups of the phenolic acid (flavanols, flavanones, isoflavones, flavones and flavonols). The antioxidants used by these authors presented scavenger capacity of the superoxide radical. Considering the good correlation between antioxidant concentration and the protective effect on the DNA, an analytical procedure to evaluate TAC was developed.

\subsection{Optimization of the experimental conditions}

To measure the TAC of beverages, some parameters concerning the damage on the purine base immobilized on the GCE (xanthine and $X O D$ concentration, reaction time between superoxide radical and the target molecule) were implemented in order to achieve the maximum DNA effect, but without a complete damage (non-zero $i_{\mathrm{p}}$ ). XOD concentration was studied between 0.0015 and $0.1 \mathrm{U} \mathrm{mL}^{-1}$. A range of $25-66 \%$ decrease in the $i_{\mathrm{p}}$ of guanine and adenine was observed over the XOD concentration studied. This is indicative of the effectiveness of XOD on the generation of the superoxide radical. At an adenine-biosensor, a $62 \%$ decrease in $i_{\mathrm{p}}$ was observed when the XOD concentration was increased from $0.0015 \mathrm{U} \mathrm{mL}^{-1}$ to $0.07 \mathrm{U} \mathrm{mL}^{-1}$. At higher XOD concentration, $i_{\mathrm{p}}$ was observed to remains essentially unchanged. Considering that the lowest XOD concentration was $0.0015 \mathrm{U} \mathrm{mL}^{-1}$, this XOD concentration was used for the next optimisation steps for the adenine biosensor. Similar results were obtained with the guanine-biosensor. The increase of XOD concentration on the reactive system generates high damage on the DNA as indicated by a decrease of 

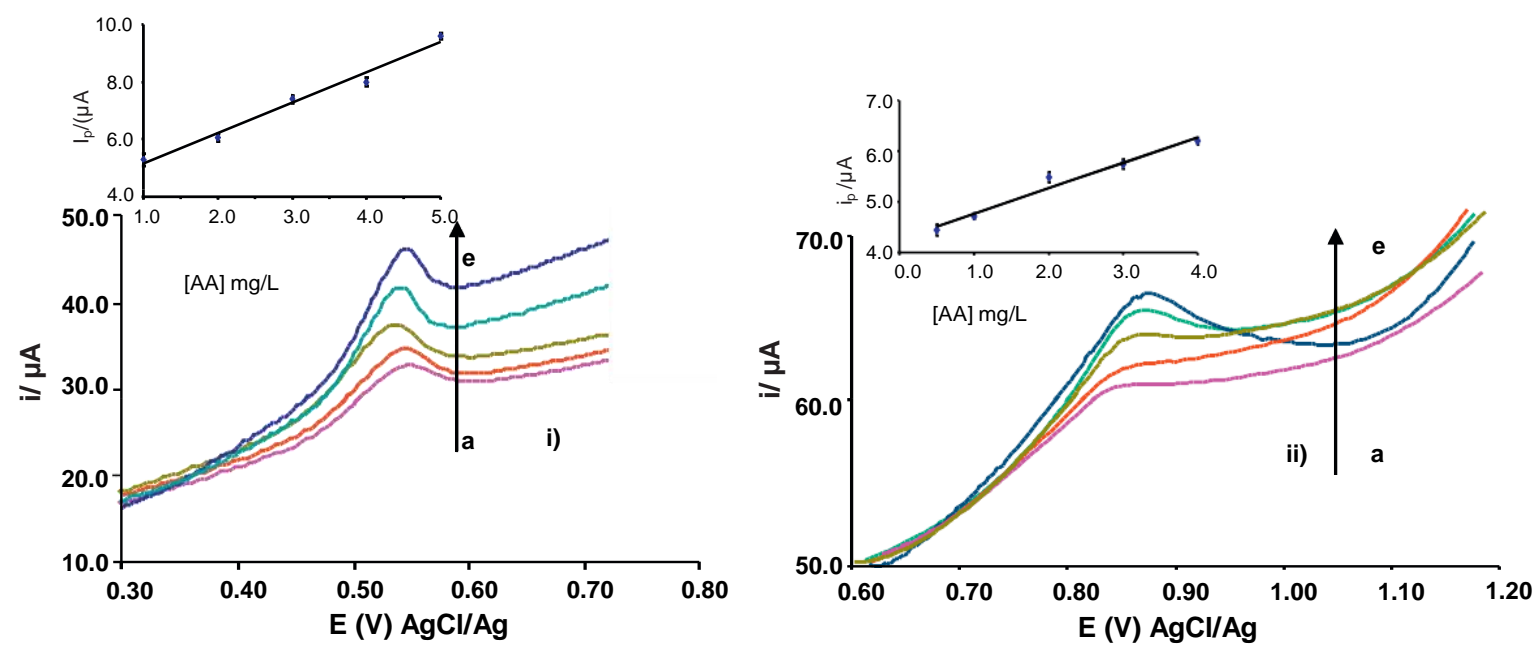

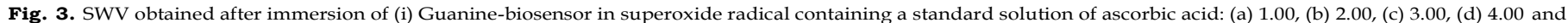

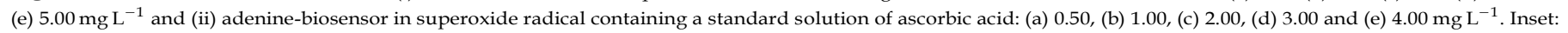
relationship between $i_{\mathrm{p}}$ and ascorbic acid concentration.

$22-60 \%$ in $i_{\mathrm{p}}$. At $\mathrm{XOD}$ concentration higher than $0.008 \mathrm{UmL}^{-1}, i_{\mathrm{p}}$ was observed to remain similar, so this value was used for the next experiments.

For both purine-based biosensors (guanine and adenine) xanthine concentration was ranged between 10 and $800 \mu \mathrm{mol} \mathrm{L}^{-1}$. With the increase of xanthine concentration a decrease between $57 \%$ and $66 \%$ in the $i_{p}$ of guanine and adenine was observed, however, the decrease of the $i_{\mathrm{p}}$ in all range of xanthine concentration studied was very similar and remained essentially unchanged. Therefore, to be more cost effective, the lowest xanthine concentration of $10 \mu \mathrm{mol} \mathrm{L}^{-1}$ was used in the next optimisation step. Reaction time between the superoxide radical and the purine bases immobilized on the GCE depends of the half-life time of the generated ROS, so this parameter is an important feature to optimize. In this study the incubation time were ranged from 0 to $120 \mathrm{~s}$. Fig. 2 shows the correlation between the damage on the purine base produced by the superoxide radical (correlated with the $i_{\mathrm{p}}$ values) and the incubation time. A more than $50 \%$ decrease in the $i_{p}$ was observed with an increase of the reaction time from 0 to $120 \mathrm{~s}$. However, there was no complete damage of DNA as indicated by the non-zero $i_{p}$ results shown in Fig. 2. The lower $i_{p}$ obtained at the adenine biosensor than the guanine biosensor indicates more damage at the former. However, de-los-Santos Álvarez et al. (2007) reported more damage of guanine than adenine at a pyrolic graphite electrode in a neutral and alkaline aqueous solutions. The incubation time of $120 \mathrm{~s}$ was chosen for allexperiments.

\subsection{Determination of TAC}

Foodstuff constitutes an excellent source of exogenous antioxidants to counteract the alteration of lipids in cellular membranes, protein, enzymes, carbohydrates and DNA promoted by ROS. Antioxidants, such as, ascorbic acid, and phenol-derived compounds are natural components of fruits and beverages (tea and wine). For theevaluation of the TAC of flavoured waters, fiveantioxidantsincludingascorbicacid, gallicacid, caffeicacid, coumaricacid and resveratrol were used. Ascorbic acid is a water-soluble vitamin, is considered a powerful antioxidant and plays a key rolein the protection against biological oxidation processes participating in many metabolic reactions (Mello and Kubota, 2007). Gallic, caffeic and coumaric acid are phenolic acids with a large protective action. Phenolic acids include several groups such as thehydroxybenzoic acid (gallic acid) and the hydroxycinnamic acid (caffeic and coumaric acid). In general, the antioxidant activity of the phenolic-derived compounds is determined by some properties, such as, free-radical scanvengers (Thavasi et al., 2006). Resveratrol is a polyphenolic natural product, derived stilbene that exists in various foods and beverages, has attracted increasing attention over the past decade because of its multiple beneficial properties, including chemopreventive and antitumor activities (Fulda, 2010). Linearity studies between the five antioxidants and $i_{p}$ of guanine and adenine oxidation were carried out. Fig. $3 i$ and ii shows the SWV of electrochemical current obtained after immersing the

Table 1

Analytical feature obtained for the 5 antioxidants standards.

\begin{tabular}{|c|c|c|c|c|c|}
\hline Parameters & Ascorbic acid & Gallic acid & Caffeic acid & Coumaric acid & Resveratrol \\
\hline \multicolumn{6}{|l|}{ Guanine-GCE } \\
\hline Linear range $\left(\mathrm{mgL}^{-1}\right)$ & $1.00-5.00$ & $0.10-1.00$ & $0.1-1.00$ & $0.50-1.00$ & $0.10-0.50$ \\
\hline Slope $\left(A \mathrm{mg}^{-1} \mathrm{~L}\right)$ & $1.05 \times 10^{-6}$ & $5.38 \times 10^{-6}$ & $5.23 \times 10^{-6}$ & $7.33 \times 10^{-6}$ & $1.27 \times 10^{-5}$ \\
\hline Intercept (A) & $4.11 \times 10^{-6}$ & $4.66 \times 10^{-6}$ & $4.25 \times 10^{-6}$ & $2.09 \times 10^{-6}$ & $1.92 \times 10^{-6}$ \\
\hline Correlation coefficient $(n=5)$ & 0.990 & 0.980 & 0.987 & 0.993 & 0.998 \\
\hline $\operatorname{RSD}(\%)\left(\mathrm{mgL}^{-1}\right)$ & $3.43(2.00)$ & $2.36(0.30)$ & $2.96(0.50)$ & $1.05(0.70)$ & $3.86(0.20)$ \\
\hline LOD & 0.77 & 0.10 & 0.10 & 0.08 & 0.06 \\
\hline \multicolumn{6}{|l|}{ Adenine-GCE } \\
\hline Linear range $\left(\mathrm{mgL}^{-1}\right)$ & $0.50-4.00$ & $0.50-0.90$ & $0.10-0.50$ & $0.10-0.50$ & $0.10-0.50$ \\
\hline Slope $\left(\mathrm{A} \mathrm{mg} \mathrm{m}^{-1} \mathrm{~L}\right)$ & $5.02 \times 10^{-7}$ & $9.40 \times 10^{-6}$ & $1.30 \times 10^{-5}$ & $6.49 \times 10^{-6}$ & $1.11 \times 10^{-5}$ \\
\hline Intercept (A) & $4.26 \times 10^{-6}$ & $8.00 \times 10^{-8}$ & $1.74 \times 10^{-6}$ & $2.99 \times 10^{-6}$ & $3.02 \times 10^{-6}$ \\
\hline Correlation coefficient $(n=5)$ & 0.985 & 0.993 & 0.995 & 0.998 & 0.994 \\
\hline RSD (\%) & $1.00(2.00)$ & $2.11(0.70)$ & $4.00(0.30)$ & $4.93(0.20)$ & $6.43(0.20)$ \\
\hline LOD & 0.50 & 0.06 & 0.05 & 0.02 & 0.10 \\
\hline
\end{tabular}


Table 2

AC values obtained for the flavours and flavoured waters using a guanine-GCE and adenine-GCE ( $\mathrm{mg} \mathrm{L}^{-1}$ ).

\begin{tabular}{|c|c|c|c|c|c|c|c|c|c|c|c|}
\hline \multirow[t]{2}{*}{ Brand } & \multirow[t]{2}{*}{ Sample } & \multicolumn{5}{|l|}{ Adenine-GCE } & \multicolumn{5}{|l|}{ Guanine-GCE } \\
\hline & & Ascorbic acid & Gallic acid & Caffeic acid & Coumaric acid & Resveratrol & Ascorbic acid & Gallic acid & Caffeic acid & Coumaric acid & Resveratrol \\
\hline \multirow[t]{6}{*}{ Flavour } & Lemon & $169.52 \pm 11.20$ & $55.22 \pm 3.90$ & $25.93 \pm 2.82$ & $32.68 \pm 5.64$ & $25.53 \pm 2.93$ & $93.14 \pm 19.93$ & $20.96 \pm 3.89$ & $16.02 \pm 4.00$ & $47.36 \pm 3.31$ & $17.01 \pm 1.89$ \\
\hline & Tangerine & $131.6 \pm 1.16$ & $39.14 \pm 0.06$ & $14.30 \pm 0.04$ & $9.39 \pm 0.09$ & $13.43 \pm 0.05$ & $220 \pm 26.47$ & $32.71 \pm 9.07$ & $41.49 \pm 9.33$ & $68.40 \pm 7.71$ & $29.01 \pm 4.40$ \\
\hline & Apple & $202.69 \pm 55.08$ & $56.99 \pm 2.94$ & $27.21 \pm 2.13$ & $35.25 \pm 4.26$ & $26.86 \pm 2.21$ & $177.05 \pm 3.10$ & $24.33 \pm 0.60$ & $32.87 \pm 0.62$ & $61.28 \pm 0.51$ & $24.95 \pm 0.29$ \\
\hline & Strawberry & $163.75 \pm 4.23$ & $37.43 \pm 3.43$ & $13.06 \pm 2.48$ & $6.90 \pm 0.97$ & $12.14 \pm 2.58$ & $186 \pm 29.03$ & $9.86 \pm 1.66$ & $2.30 \pm 5.83$ & $32.22 \pm 4.81$ & $8.37 \pm 2.75$ \\
\hline & Gooseberry & $169.42 \pm 59.30$ & $55.22 \pm 3.17$ & $25.93 \pm 2.29$ & $32.67 \pm 4.59$ & $25.52 \pm 2.38$ & $74.81 \pm 7.18$ & $4.38 \pm 0.89$ & $12.34 \pm 1.29$ & $44.32 \pm 1.81$ & $15.27 \pm 6.73$ \\
\hline & Lime & $126.00 \pm 6.77$ & $39.44 \pm 4.10$ & $14.52 \pm 2.96$ & $9.82 \pm 0.32$ & $13.66 \pm 3.08$ & $133.52 \pm 34.21$ & $15.84 \pm 2.68$ & $24.13 \pm 2.87$ & $54.06 \pm 5.67$ & $20.83 \pm 3.24$ \\
\hline \multirow[t]{4}{*}{ A } & 1 Lemon & $13.91 \pm 2.78$ & $3.23 \pm 0.11$ & $1.64 \pm 0.08$ & $2.32 \pm 0.16$ & $1.63 \pm 0.08$ & $15.05 \pm 2.50$ & $2.43 \pm 0.09$ & $2.13 \pm 0.57$ & $4.09 \pm 0.41$ & $1.83 \pm 0.24$ \\
\hline & 2 Mango & $13.31 \pm 4.43$ & $3.16 \pm 0.04$ & $1.59 \pm 0.03$ & $2.21 \pm 0.5$ & $1.58 \pm 0.03$ & $9.98 \pm 5.35$ & $1.44 \pm 0.04$ & $0.88 \pm 0.32$ & $3.25 \pm 0.89$ & $1.35 \pm 0.51$ \\
\hline & 3 Strawberry & $16.08 \pm 2.06$ & $3.33 \pm 0.12$ & $1.71 \pm 0.09$ & $2.46 \pm 0.18$ & $1.71 \pm 0.09$ & $6.58 \pm 1.78$ & $0.77 \pm 0.05$ & $0.62 \pm 0.04$ & $2.69 \pm 0.30$ & $1.03 \pm 0.17$ \\
\hline & 4 Natural & - & - & - & - & - & - & - & - & $0.01 \pm 0.04$ & - \\
\hline \multirow[t]{3}{*}{ B } & 5 Pineapple/orange & $1.03 \pm 0.03$ & $2.53 \pm 0.20$ & $1.13 \pm 0.14$ & $1.30 \pm 0.28$ & $1.10 \pm 0.15$ & $8.00 \pm 0.48$ & $1.05 \pm 0.09$ & $0.94 \pm 0.06$ & $2.92 \pm 0.08$ & $1.17 \pm 0.05$ \\
\hline & 6 Lemon & $1.29 \pm 0.06$ & $2.39 \pm 0.08$ & $1.03 \pm 0.06$ & $1.09 \pm 0.11$ & $1.00 \pm 0.06$ & $4.39 \pm 0.13$ & $0.34 \pm 0.03$ & $0.45 \pm 0.05$ & $2.32 \pm 0.02$ & $0.82 \pm 0.01$ \\
\hline & 7 Natural & - & - & - & - & - & - & - & - & $0.05 \pm 0.04$ & - \\
\hline \multirow[t]{4}{*}{ c } & 8 Lemon/magnesium & $4.22 \pm 0.26$ & $2.38 \pm 0.06$ & $1.02 \pm 0.05$ & $1.07 \pm 0.09$ & $0.99 \pm 0.05$ & $5.80 \pm 2.02$ & $0.48 \pm 0.03$ & $3.20 \pm 0.27$ & $1.62 \pm 0.34$ & $0.42 \pm 0.09$ \\
\hline & 9 Apple/white tea & $3.69 \pm 0.99$ & $2.52 \pm 0.25$ & $1.12 \pm 0.18$ & $1.28 \pm 0.36$ & $1.09 \pm 0.19$ & $14.69 \pm 5.21$ & $2.36 \pm 0.02$ & $2.54 \pm 1.4$ & $4.03 \pm 0.86$ & $1.80 \pm 0.05$ \\
\hline & 10 Pineapple/fibre & $1.70 \pm 0.25$ & $2.45 \pm 0.40$ & $1.07 \pm 0.29$ & $1.18 \pm 0.57$ & $1.04 \pm 0.30$ & $4.86 \pm 0.53$ & $0.44 \pm 0.10$ & $1.54 \pm 0.53$ & $2.40 \pm 0.09$ & $0.87 \pm 0.05$ \\
\hline & 11 Natural & - & - & - & - & - & - & - & & $0.05 \pm 0.03$ & - \\
\hline \multirow[t]{4}{*}{$\mathrm{D}$} & 12 Apple & $0.33 \pm 0.07$ & $0.77 \pm 0.52$ & $1.30 \pm 0.38$ & $1.65 \pm 0.76$ & $1.28 \pm 0.39$ & $0.95 \pm 0.06$ & $0.67 \pm 0.02$ & $0.70 \pm 0.03$ & $0.60 \pm 0.04$ & $0.15 \pm 0.03$ \\
\hline & 13 Orange/peach & $0.82 \pm 0.04$ & $0.38 \pm 0.21$ & - & $1.09 \pm 0.31$ & $0.99 \pm 0.16$ & $0.68 \pm 0.03$ & $0.38 \pm 0.07$ & $0.41 \pm 0.05$ & $0.80 \pm 0.02$ & $0.33 \pm 0.05$ \\
\hline & 14 Lemon & $0.48 \pm 0.09$ & $0.34 \pm 0.11$ & $0.99 \pm 0.08$ & $1.02 \pm 0.15$ & $0.96 \pm 0.08$ & $0.81 \pm 0.06$ & $0.62 \pm 0.09$ & $0.60 \pm 0.51$ & $0.75 \pm 0.08$ & $0.96 \pm 0.04$ \\
\hline & 15 Natural & - & - & - & - & - & - & - & - & - & - \\
\hline \multirow[t]{5}{*}{ E } & 16 Lemon & $6.12 \pm 0.04$ & $1.96 \pm 0.45$ & $0.72 \pm 0.33$ & $0.47 \pm 0.65$ & $0.67 \pm 0.34$ & $10.71 \pm 0.61$ & $1.58 \pm 0.09$ & $1.76 \pm 0.48$ & $3.37 \pm 0.93$ & $1.42 \pm 0.53$ \\
\hline & 17 Orange/raspberry & $7.31 \pm 0.95$ & $2.68 \pm 0.66$ & $1.24 \pm 0.48$ & $1.52 \pm 0.06$ & $1.22 \pm 0.50$ & $14.09 \pm 2.63$ & $2.24 \pm 0.51$ & $1.91 \pm 0.58$ & $3.93 \pm 0.44$ & $1.74 \pm 0.25$ \\
\hline & 18 Peach/pineapple & $6.55 \pm 0.77$ & $2.72 \pm 0.28$ & $1.26 \pm 0.20$ & $1.57 \pm 0.21$ & $1.24 \pm 0.21$ & $14.20 \pm 3.42$ & $2.26 \pm 0.27$ & $2.34 \pm 0.22$ & $3.95 \pm 0.57$ & $1.75 \pm 0.32$ \\
\hline & 19 Guava/lime & $6.56 \pm 0.57$ & $2.45 \pm 0.12$ & $1.07 \pm 0.09$ & $1.18 \pm 0.18$ & $1.04 \pm 0.09$ & $6.11 \pm 0.40$ & $1.70 \pm 0.03$ & $1.07 \pm 0.79$ & $1.58 \pm 3.16$ & $1.17 \pm 0.04$ \\
\hline & 20 Natural & - & - & - & - & - & - & - & - & - & - \\
\hline \multirow[t]{6}{*}{$\mathrm{F}$} & 21 Lemon/green tea & $4.14 \pm 0.21$ & $2.28 \pm 0.02$ & $0.95 \pm 0.01$ & $0.94 \pm 0.03$ & $0.91 \pm 0.01$ & $11.10 \pm 1.21$ & $1.66 \pm 0.21$ & $1.82 \pm 0.44$ & $3.44 \pm 0.86$ & $1.46 \pm 0.04$ \\
\hline & 22 Raspberry/ginseng & $3.58 \pm 0.26$ & $2.39 \pm 0.12$ & $1.03 \pm 0.09$ & $1.10 \pm 0.18$ & $1.00 \pm 0.09$ & $12.01 \pm 0.24$ & $1.83 \pm 0.05$ & $1.67 \pm 0.81$ & $3.59 \pm 0.04$ & $1.55 \pm 0.02$ \\
\hline & 23 Peach/white tea & $2.66 \pm 0.18$ & $2.03 \pm 0.09$ & $0.77 \pm 0.06$ & $0.58 \pm 0.13$ & $0.73 \pm 0.07$ & $12.42 \pm 0.47$ & $1.91 \pm 0.42$ & $1.61 \pm 0.63$ & $3.66 \pm 0.36$ & $1.58 \pm 0.21$ \\
\hline & 24 Mango/ginkgo beloba & $1.62 \pm 0.30$ & $2.22 \pm 0.12$ & $0.91 \pm 0.09$ & $0.85 \pm 0.18$ & $1.87 \pm 0.09$ & $15.92 \pm 1.51$ & $2.60 \pm 0.29$ & $2.40 \pm 0.64$ & $4.24 \pm 0.25$ & $1.92 \pm 0.04$ \\
\hline & $25 \mathrm{Melon} / \mathrm{mint}$ & $2.10 \pm 0.05$ & $2.19 \pm 0.15$ & $0.88 \pm 0.11$ & $0.80 \pm 0.21$ & $1.84 \pm 0.11$ & $8.17 \pm 1.39$ & $1.08 \pm 0.06$ & $1.26 \pm 0.02$ & $2.95 \pm 0.73$ & $1.18 \pm 0.02$ \\
\hline & 26 Natural & & - & & & - & - & - & 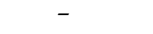 & 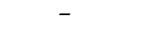 & 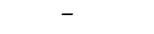 \\
\hline \multirow[t]{5}{*}{ G } & 27 Lemon & $19.28 \pm 1.44$ & $3.37 \pm 0.24$ & $1.74 \pm 0.18$ & $2.52 \pm 0.35$ & $1.74 \pm 0.18$ & $18.77 \pm 1.61$ & $3.15 \pm 0.31$ & $3.29 \pm 0.81$ & $4.71 \pm 0.27$ & $2.19 \pm 0.05$ \\
\hline & 28 Lime & $5.01 \pm 0.20$ & $2.76 \pm 0.08$ & $1.29 \pm 0.06$ & $1.63 \pm 0.12$ & $1.27 \pm 0.06$ & $10.92 \pm 1.41$ & $1.62 \pm 0.28$ & $1.38 \pm 0.68$ & $3.41 \pm 0.23$ & $1.44 \pm 0.13$ \\
\hline & 29 Apple & $11.23 \pm 0.96$ & $3.17 \pm 0.26$ & $1.59 \pm 0.19$ & $2.22 \pm 0.38$ & $1.58 \pm 0.20$ & $15.98 \pm 0.88$ & $2.61 \pm 0.17$ & $2.46 \pm 0.70$ & $4.25 \pm 0.15$ & $1.92 \pm 0.08$ \\
\hline & 30 Peach & $21.25 \pm 0.96$ & $2.45 \pm 0.13$ & $1.07 \pm 0.09$ & $1.18 \pm 0.19$ & $1.04 \pm 0.10$ & $14.87 \pm 0.61$ & $0.44 \pm 0.51$ & $0.67 \pm 0.77$ & $2.40 \pm 0.43$ & $0.87 \pm 0.01$ \\
\hline & 31 Natural & - & - & - & - & - & - & - & - & - & $0.04 \pm 0.02$ \\
\hline $\mathrm{H}$ & $\begin{array}{l}32 \text { Lemon } \\
33 \text { Natural }\end{array}$ & $\begin{array}{c}4.03 \pm 0.40 \\
-\end{array}$ & $\begin{array}{c}2.48 \pm 0.44 \\
-\end{array}$ & $\begin{array}{c}1.09 \pm 0.32 \\
-\end{array}$ & $\begin{array}{c}1.23 \pm 0.63 \\
-\end{array}$ & $\begin{array}{c}1.06 \pm 0.33 \\
-\end{array}$ & $\begin{array}{c}8.92 \pm 0.75 \\
-\end{array}$ & $\begin{array}{c}1.23 \pm 0.54 \\
-\end{array}$ & $\begin{array}{c}0.92 \pm 0.49 \\
-\end{array}$ & $\begin{array}{c}3.08 \pm 0.46 \\
-\end{array}$ & $\begin{array}{c}1.25 \pm 0.06 \\
-\end{array}$ \\
\hline \multirow[t]{4}{*}{ I } & 34 Lemon & $3.91 \pm 0.73$ & $2.55 \pm 0.20$ & $1.15 \pm 0.14$ & $1.33 \pm 0.29$ & $1.12 \pm 0.15$ & $9.48 \pm 0.91$ & $1.34 \pm 0.18$ & $1.16 \pm 0.09$ & $3.17 \pm 0.15$ & $1.31 \pm 0.09$ \\
\hline & 35 Green apple & $0.37 \pm 0.21$ & $2.61 \pm 0.39$ & $1.19 \pm 0.28$ & $1.42 \pm 0.56$ & $1.16 \pm 0.29$ & $14.48 \pm 0.57$ & $2.31 \pm 0.11$ & $2.15 \pm 0.07$ & $4.00 \pm 0.09$ & $1.78 \pm 0.05$ \\
\hline & 36 Strawberry & $1.25 \pm 0.05$ & $2.05 \pm 0.11$ & $0.78 \pm 0.08$ & $0.61 \pm 0.16$ & $0.74 \pm 0.08$ & $15.19 \pm 1.09$ & $2.45 \pm 0.21$ & $2.42 \pm 0.25$ & $4.11 \pm 0.18$ & $1.85 \pm 0.10$ \\
\hline & 37 Natural & - & - & - & - & - & - & - & - & - & - \\
\hline J & $\begin{array}{l}38 \text { Lemon } \\
39 \text { Natural }\end{array}$ & $2.10 \pm 0.21$ & $\begin{array}{c}2.06 \pm 0.03 \\
-\end{array}$ & $\begin{array}{c}0.79 \pm 0.02 \\
-\end{array}$ & $\begin{array}{c}0.62 \pm 0.04 \\
-\end{array}$ & $\begin{array}{c}0.75 \pm 0.02 \\
-\end{array}$ & $\begin{array}{c}10.49 \pm 0.23 \\
-\end{array}$ & $\begin{array}{c}1.54 \pm 0.04 \\
\quad\end{array}$ & $\begin{array}{c}1.41 \pm 0.05 \\
\quad\end{array}$ & $\begin{array}{c}3.34 \pm 0.04 \\
-\end{array}$ & $\begin{array}{c}1.40 \pm 0.02 \\
\quad\end{array}$ \\
\hline
\end{tabular}


purine-biosensor on the superoxide radical containing increasing concentration of ascorbic acid. As expected, the oxidation current of guanine and adenine increased when the concentration of ascorbic acid increased. Similar voltammograms were obtained when the other antioxidants (resveratrol, gallic, caffeic and coumaric acid) were used with the both DNA-biosensors (guanine and adenine).

Table 1 presents a summary of analytical parameters of the guanine and adenine biosensors obtained after being immersed in the respective five antioxidants used. Among them, ascorbic acid showed the widest linear range from 1.00 to $5.00 \mathrm{mg} \mathrm{L}^{-1}$ at guanine-GCE and $0.50-4.00 \mathrm{mg} \mathrm{L}^{-1}$ at adenine-GCE. The other antioxidants presented a narrow linear range, $0.10-1.00 \mathrm{mg} \mathrm{L}^{-1}$ of gallic acid or caffeic acid, $0.10-0.50 \mathrm{mg} \mathrm{L}^{-1}$ of resveratrol and $0.50-1.00 \mathrm{mg} \mathrm{L}^{-1}$ of coumaric acid when the guanine biosensor was used. For the adenine biosensor, the linear range was from 0.10 to $0.50 \mathrm{mg} \mathrm{L}^{-1}$ for the antioxidants caffeic acid, coumaric acid and resveratrol, and from 0.50 to $0.90 \mathrm{mg} \mathrm{L}^{-1}$ for gallic acid. RSD values were below $10 \%$ confirmed the high precision of the methods.

Table 2 shows the TAC values expressed in $\mathrm{mg} \mathrm{L}^{-1}$ of ascorbic acid, gallic acid, caffeic acid, coumaric acid and resveratrol. All flavours and flavoured waters were observed to show antioxidant capacity; except the natural waters. Flavours that showed the highest TAC values are fruit extracts that contain several concentrated antioxidant compounds. Using the adenine and guanine GCE the highest TAC values were found with the ascorbic acid standard. At the adenine biosensor apple, fallowed by lemon, gooseberry strawberry, tangerine and lime were the flavours that showed the highestTACvalues. Attheguanine-biosensortangerineshowed the highest TAC value, fallowed by strawberry, apple, lime, lemon and gooseberry.

When the adenine-biosensor was applied to the analysis of flavoured waters, brand G showed the highest TAC values (sample 27 and 30), maybe because this brand had in its composition vitamin C (sample 28 has novitamin and the TAC value was lower than the other samples from the same brand). Brand A also presented higherTACvaluesand theothercommercial brandspresented TAC values ranging between $0.33 \mathrm{mg} \mathrm{L}^{-1}$ and $7.31 \mathrm{mg} \mathrm{L}^{-1}$ with the standard ascorbic acid. Using the antioxidant ascorbic acid the lowest TAC value was obtained from the brand D (sample 12-14) and sample 35. Analysing TAC results obtained using the water brands (brand A, B, C, D, E, F and I) it was verified that the TAC values obtained within the same brand were similar, hence, the AdenineGCE might not discriminate the different flavours present in same brand. Using the gallic acid standard the TAC values ranged from 37 to $57 \mathrm{mg} \mathrm{L}^{-1}$ for the flavours and $0.34-3.37 \mathrm{mg} \mathrm{L}^{-1}$ for the flavoured waters. The lowest TAC values were obtained in brand D (samples 12-14) and the highest TAC contents were from brand A (samples 1-3). With the caffeic acid antioxidant the TAC ranged from 13 to $27 \mathrm{mg} \mathrm{L}^{-1}$ and $0.72-1.74 \mathrm{mg} \mathrm{L}^{-1}$ in flavours and flavoured waters respectively. Similar results were obtained with the other standard antioxidants, coumaric acid and resveratrol. TAC values obtained with the ascorbic acid were larger than the other four antioxidants (gallicacid, caffeicacid, coumaricacid and resveratrol) that presented a narrow TAC levels. Theses differences obtained between the ascorbic acid and the other antioxidants can be elucidated because the ascorbic acid is a powerful antioxidant and in this study presented a larger linear range.

A similar behaviour was observed with the guanine-GCE and using the standard ascorbic acid, brand G (samples 27) presented also the highest TAC values fallowed by brand $F$, brand $A$ and brand $\mathrm{H}$. TAC values ranged between 0.68 and $18.7 \mathrm{mgL}^{-1}$ equivalents of ascorbic acid. It was verified that TAC results obtained within the same brand were similar (analogous to that at the adenine biosensor) with the exception of brand C. Considering that sample 9 (from brand C) had two added ingredient; apple and white tea a higher TAC value was expected compared with the other samples of brand
C. For other antioxidants, the TAC values ranged from $0.34 \mathrm{mgL}^{-1}$ to $3.15 \mathrm{mg} \mathrm{L}^{-1}$ and $0.41 \mathrm{mg} \mathrm{L}^{-1}-3.20 \mathrm{mg} \mathrm{L}^{-1}$ or between $0.01 \mathrm{mg} \mathrm{L}^{-1}$ and $4.71 \mathrm{mg} \mathrm{L}^{-1}$ and from $0.33 \mathrm{mg} \mathrm{L}^{-1}$ to $2.19 \mathrm{mg} \mathrm{L}^{-1}$ for the gallic acid, caffeic acid, coumaric acid and resveratrol, respectively. Larger TAC values were obtained with the ascorbic acid antioxidant and the other four antioxidants presented a narrow TAC range, a similar behaviour was obtained with the adenine-GCE.

By analysing the results in Table 2, the applications of adenine and guanine-immobilised GCEs to the evaluation of TAC in beverages were demonstrated. Standards off all antioxidants were available for use in the TAC determination in this study. Among them, we recommend ascorbic acid should be used as a common standard in the determination of TAC of foodstuff and beverages as it exhibited the widest linear calibration range at both the guanine and adenine biosensors.

\section{Conclusion}

Adenine and guanine-immobilised GCEs for the evaluation of TAC in beverages was developed. The methodology is based on the interaction of adenine or guanine with the superoxide radical generated by the xanthine/xanthine oxidase system. Five standard antioxidants (ascorbic acid, gallic acid, caffeic acid, coumaric acid and resveratrol) were used in order to protect adenine and guanine base. Ascorbic acid presented the highest TAC values and seems to be the most sensitive standard capable to discriminate the several ingredients added to the waters.

The biosensors described in this study have some advantages over the conventional methodologies such as a shorter detection time, a smaller sample volume, higher accuracy and a high simplicity. In addition, coloured samples can be directly used for the measurement without pretreatment. The use of these biosensors is closer to biological systems, with a nucleotide being damaged by free radical.

\section{Acknowledgements}

M. Fátima Barroso is grateful to Fundação para a Ciência e a Tecnologia for a Ph.D. grant (SFRH/BD/29440/2006). The authors thank Frize for providing flavours samples.

\section{References}

ANIRSF, 2010. Associação Nacional dos industriais de refrigerantes e sumos de frutos, 2010. Informar $n^{\circ} 29$. From the website: $w w w$ anirsf.pt (accssed 03.11.10).

Barroso, M.F., de-los-Santos-Álvarez, N., Lobo-Castan ón, M.J., Miranda-Ordieres, A.J., Delerue-Matos, C., Oliveira, M.B.P.P., Tuñón-Blanco, P., 2011. Biosens. Bioelectron. 26 (5), 2396-2401.

Barroso, M.F., Silva, A., Ramos, S., Oliva-Teles, M.T., Delerue-Matos, C., Sales, M.G.F., Oliveira, M.B.P.P., 2009. Food Chem. 116 (2), 580-589.

Beissenhirtz, M.K., Scheller, F.W., Lisdat, F., 2004. Anal. Chem. 76 (16), 4665-4671.

Benherlal, P.S., Arumughan, C., 2008. Mutat. Res. -Fundam. Mol. Mech. Mutagent. $648(1-2), 1-8$.

Brett, A.M.O., Matysik, F.-M., 1997. J. Electroanal. Chem. 429, 95-99.

Brett, C.M.A., Brett, A.M.O., Serrano, S.H.P., 1994. J. Electroanal. Chem. 366 (1-2), 225-231.

Burrows, C.J., Muller, J.G., 1998. Chem. Rev. 98 (3), 1109-1151.

Campanella, L., Bonanni, A., Finotii, E., Tomassetti, M., 2004. Biosens. Bioelectron. 19 (7), 641-651.

Chen, J., Wollenberger, U., Lisdat, F., Ge, B., Scheller, F.W., 2000. Sens. Actuators BChem. 70 (1-3), 115-120.

Chiti, G., Marrazza, G., Mascini, M., 2001. Anal. Chim. Acta 427 (2), 155-164.

de-los-Santos-Álvarez, N., de-los-Santos-Álvarez, P., Lobo-Castanon, M.J., Lopez, R., Miranda-Ordieres, A.J., Tunon-Blanco, P., 2007. Electrochem. Commun. 9 (8), 1862-1866.

de-los-Santos-Álvarez, P., Lobo-Castañón, M.J., Miranda-Ordieres, A.J., TuñónBlanco, P., 2002. Anal. Chem. 74 (14), 3342-3347.

Emregül, E., 2005. Anal. Bioanal. Chem. 383 (6), 947-954

Endo, K., Miyasaka, T., Mochizuki, S., Aoyagi, S., Himi, N., Asahara, H., Tsujioka, K., Sakai, K., 2002. Sens. Actuators B-Chem. 83 (1-3), 30-34.

Fojta, M., Kubicarova, T., Palecek, E., 2000. Biosens. Bioelectron. 15 (3-4), 107-115. Freidman, K.A., Heller, A., 2004. J. Am. Chem. Soc. 126 (8), 2368-2371.

Fulda, S., 2010. Drug Discov. Today 15 (17-18), 757-765. 
Ge, B., Lisdat, F., 2002. Anal. Chim. Acta 454 (1), 53-64.

Gobi, K.V., Mizutani, F., 2000. J. Electroanal. Chem. 484 (2), 172-181.

Halliwell, B., Gutteridge, J.M., Cross, C.E., 1992. J. Lab. Clin. Med. 119 (6), 598-620.

Ignatov, S., Shishniashvili, D., Ge, B., Scheller, F.W., Lisbat, F., 2002. Biosens. Bioelectron. 17 (3), 191-199.

Laranjinha, J., 2009. Oxidative Stress: From the 1980s to Resent Update in Oxidative Stress, Inflammation and Angiogenesis in the Metabolic Syndrome, First ed. Springer.

Liu, J.F., Roussel, C., Lagger, G., Tacchini, P., Girault, H.H., 2005. Anal. Chem. 77 (23), 7687-7694.

Liu, J.F., Su, B., Lagger, G., Tacchini, P., Girault, H.H., 2006. Anal. Chem. 78 (19), 6879-6884.
Marrazza, G., Chianella, I., Mascini, M., 1999. Anal. Chim. Acta 387 (3), 297-307. McNeil, C.J., Dale Athey, D., Ho, W.O., 1995. Biosens. Bioelectron. 10 (1-2), 75 83.

Mello, L.D., Hernandez, S., Marrazza, G., Mascini, M., Kubota, L.T., 2006. Biosens. Bioelectron. 21 (7), 1374-1382.

Mello, L.D., Kubota, L.T., 2007. Talanta 72 (2), 335-348.

Qian, P., Ai, S.Y., Yin, H.S., Li, J.H., 2010. Microchim. Acta 168 (3-4), 347-354.

Rice, M.E., Galus, Z., Adams, R.N., 1983. J. Electroanal. Chem. 143 (1-2), 89-102.

Sanchez-Moreno, C., 2002. Food Sci. Technol. Int. 8 (3), 121-137.

Thavasi, V., Leong, L.P., Bettens, R.P.A., 2006. J. Phys. Chem. A 110 (14), 49184923. 